\title{
GERENCIAMENTO DE RISCOS NA CADEIA DE SUPRIMENTOS DE MICRO E PEQUENAS EMPRESAS TÊXTEIS: DISCUSSÃO EXPLORATÓRIA SOBRE OPORTUNIDADES DE PESQUISA
}

DOI: $10.14211 / 41172$

Artigo recebido em: 25/08/2014. Artigo aprovado em:01/10/2014.

\begin{abstract}
Francisco Carlos Fernandes - Fundação Universidade Regional de Blumenau ${ }^{1}$ Franciele Wrubel - Fundação Universidade Regional de Blumenau ${ }^{2}$ Lara Fabiana Dallabona - Fundação Universidade Regional de Blumenau ${ }^{3}$
\end{abstract}

\begin{abstract}
Resumo: O estudo objetiva identificar e analisar os riscos e mecanismos de gerenciamento de riscos inerentes à cadeia de suprimentos e logística de micro e pequenas empresas sediadas em Blumenau-SC, além de proporcionar discussão exploratória sobre oportunidades de pesquisas. Para tanto, desenvolveu-se pesquisa exploratória e qualitativa com aplicação de entrevista semiestruturada. A entrevista foi elaborada utilizando o COSO, estudos relacionados e estudos multicasos. Os resultados demonstram que os principais riscos relacionam-se com a compra, transporte, manuseio e qualidade da matéria-prima, softwares ineficientes, programação, prazos de entregas e processos complexos de importação. No que se refere aos mecanismos de gerenciamento, constatou-se o planejamento na compra de matéria-prima com qualidade e controles de pedidos. Destacaram-se possibilidades de pesquisas para explicar e explorar relações existentes na gestão de riscos logísticos/suprimentos para as micro e pequenas empresas. Maior institucionalização dessas pesquisas instigam possibilidades de comparações, discussão dos resultados e melhoramentos da gestão de riscos.
\end{abstract}

Palavras-chave: Micro e pequenas empresas, gerenciamento de riscos, cadeia de suprimentos, logística, pesquisas futuras.

\section{RISK MANAGEMENT IN THE SUPPLY CHAIN IN MICRO AND SMALL BUSINESS TEXTILE: EXPLORATORY DISCUSSION ON RESEARCH OPPORTUNITIES}

Abstract: The study aims to identify and analyze the risks and mechanisms for managing risks to the supply chain and logistics of micro and small companies based in Blumenau - SC and provide discussion on exploratory research opportunities. For this, is was developed an exploratory qualitative research with application of semi-structured interview. The interview was developed using COSO, related studies and multi-case studies. The results demonstrate that the main risks relate to the purchase, transportation, handling and quality of raw

\footnotetext{
${ }^{1}$ E.mail: fernandes.francisco.0208@gmail.com - Endereço: Rua Antônio da Veiga, 140 - Victor Konder - Blumenau - SC, CEP: 89012-900.

2 E.mail: franciele_wrubel@yahoo.com.br

${ }^{3}$ E.mail: lara_mestrado@hotmail.com
}

FERNANDES, F. C.; WRUBEL , F.; DALLABONA, L. F. Gerenciamento de riscos na cadeia de suprimentos de micro e pequenas empresas têxteis: discussão exploratória sobre oportunidades de pesquisa. Revista de Empreendedorismo e Gestão de Pequenas Empresas, v.4, n. 1, 2015. 
materials, inefficient software, programming and delivery times and complex import procedures. About management mechanisms found if planning on purchasing raw materials and quality control applications. The highlights research possibilities to explain and explore relationships in managing logistical risks/supplies for micro and small enterprises. Greater institutionalization of these searches instigates possibilities of comparisons, discussion of results and improvements in risk management.

Keywords: Micro and small companies, risk management, supply chain, logistics, future research.

\section{Introdução}

Antes de tudo, é preciso dizer que o risco está diretamente associado a perdas. O risco é definido como possibilidades de prejuízos acarretados por diversos fatores organizacionais, tanto internos quanto externos (GITMAN, 1997). Dessa forma, torna-se relevante que as organizações os gerenciem, com o objetivo de reduzir eventuais perdas financeiras.

O gerenciamento de riscos envolve uma série de etapas que incluem a identificação de riscos, medidas e avaliações preventivas, redução ou eliminação da exposição, elaboração de relatórios de riscos e outros (DE PAZ et al., 2011).

Esse gerenciamento é um tema que tem gerado discussões no âmbito acadêmico e profissional, pois em todos os ambientes, inclusive no empresarial, os riscos podem acontecer, sendo importante que as pessoas e os gestores possam geri-los e mitigá-los, independente do porte da empresa. Os controles internos da empresa podem e devem ser utilizados para isso (PAULO et al., 2007). Esses controles podem ser realizados especificamente para cada diferente área, processo e fluxo da empresa e de sua cadeia de valor.

De acordo com o Committee of Sponsoring Organizations of the Treadway Commission (COSO, 2004), a gestão de riscos pode ser aplicada em todos os tipos de atividades, em qualquer empresa, pública, privada ou em qualquer forma de empresa, independente do seu porte. Isso leva a gestão de riscos não apenas às grandes corporações, que já apresentam controle interno de riscos institucionalizado, mas também em micro e pequenas empresas que não possuem uma gestão interna tão precisa e apresentam algumas particularidades, tanto em seu processo gerencial, quanto em sua estrutura física e operacional.

FERNANDES, F. C.; WRUBEL , F.; DALLABONA, L. F. Gerenciamento de riscos na cadeia de suprimentos de micro e pequenas empresas têxteis: discussão exploratória sobre oportunidades de pesquisa. Revista de Empreendedorismo e Gestão de Pequenas 
Harland, Brenchley e Walker (2003) destacam que quando as empresas se deparam com riscos são geralmente influenciadas pela natureza da atividade, estilo individual e comportamento do administrador, sendo relevante o estudo dos riscos que envolvem suas atividades. Dessa forma, quando se trata sobre fluxo (de bens, serviços, informações e recursos financeiros) em todos os processos da empresa, não se pode deixar de associá-la à cadeia de valor proposta por Porter (1989).

Pode-se considerar a cadeia de valor como sendo o conjunto dos processos e atividades que dão valor ao produto, desde a matéria-prima até o consumidor final (PORTER, 1989). Dessa forma, uma área que está presente em toda a cadeia de valor é a logística. Ela pode ser visualizada em micro, pequenas, médias e grandes empresas.

Para Christopher (2002), logística é o processo de gerenciar estrategicamente a aquisição, movimentação e armazenagem de materiais, peças e produtos acabados (e os fluxos de informações correlatas) por meio da organização e de seus canais de marketing, de modo a maximizar a lucratividade. Essa presença também é identificada nas empresas de micro e pequeno porte, uma vez que a logística desempenha função essencial no âmbito empresarial e no desenvolvimento da economia mundial. Por tais razões, a logística precisa ser considerada em todas as atividades operacionais, internas ou externas de uma organização, ou seja, envolve a cadeia de valor interna e externa da qual a organização participa.

A cadeia logística faz parte de uma cadeia de suprimentos nas empresas. Uma cadeia de suprimentos, para Chopra e Meindl (2011, p. 03), consiste em "todas as partes envolvidas, direta ou indiretamente, na realização do pedido de um cliente". A cadeia de suprimentos inclui transportadoras, armazéns, varejistas e até mesmo os próprios clientes, e não apenas o fabricante e os fornecedores. Dentro de cada organização, assim como em um fabricante, a cadeia de suprimentos inclui todas as funções envolvidas na solicitação do cliente: desenvolvimento do produto, marketing, operações, distribuição, finanças e serviço ao cliente, não estando simplesmente limitada a estas funções (CHOPRA; MEINDL, 2011).

Conhecer as relações existentes entre os agentes da cadeia de suprimentos e da logística é importante para saber conduzir de maneira mais eficiente a 
aplicação dos recursos, a geração de valor e o planejamento para a diminuição dos riscos. Diante da contextualização, surge a pergunta de pesquisa: Quais os riscos e mecanismos de gerenciamento de riscos inerentes à cadeia de suprimentos e logística, utilizados por micro e pequenas empresas sediadas em Blumenau-SC?

Dessa forma, o estudo objetiva identificar e analisar os riscos e mecanismos de gerenciamento de riscos inerentes à cadeia de suprimentos e logística utilizados por micro e pequenas empresas sediadas em Blumenau-SC, além de proporcionar uma discussão exploratória sobre oportunidades de pesquisas.

Justifica-se o desenvolvimento do estudo considerando que no Brasil há poucas pesquisas na área de gerenciamento de riscos e principalmente em cadeia de suprimentos e logística de micro e pequenas empresas. Desta forma, este estudo busca contribuir com a análise e mitigação dos riscos dessa cadeia de suprimentos de empresas que não demonstram condições para uma estrutura administrativa complexa e/ou sofisticada, haja vista que tais empresas buscam contemplar estruturas simples, envolvendo baixo custo e atitudes que correspondem às necessidades operacionais das empresas (LEONE, 1999).

Assim, o presente estudo contribui com a descrição de métodos utilizados por empresários como forma de mitigar possíveis riscos identificados na cadeia de suprimentos e logística de indústrias que desenvolvem produtos para empresas do ramo têxtil e apresenta lacunas de pesquisas que podem ser exploradas nessa área.

\section{Referencial teórico}

Esta seção se propõe a contextualizar micro e pequenas empresas, apresentar aspectos conceituais sobre riscos e gerenciamento de riscos, bem como cadeia de suprimentos e cadeia logística.

\section{Micro e pequenas empresas}

Embora micro, pequenas e médias empresas são terminologias utilizadas alternadamente em todo o mundo, não existe uma definição comum desses termos 
(SMIT; WATKINS, 2012). De acordo com a legislação brasileira, as micro e pequenas empresas são classificadas de acordo com a receita bruta anual, sendo que para microempresa (ME), de acordo com a Lei 123/06, a receita bruta é de até $\mathrm{R} \$ 360.000,00$ e para a empresa de pequeno porte (EPP), o valor da receita bruta é de $R \$ 360.000,01$ até $R \$ 3.600 .000,00$. Já o SEBRAE caracteriza as micro e pequenas empresas quanto ao número de empregados, conforme sugere o Instituto Brasileiro de Geografia e Estatística (IBGE). Isto pode ser visualizado no quadro 1 a seguir:

\begin{tabular}{|l|l|l|}
\hline \multicolumn{1}{|c|}{ CLASSIFICAÇÃO } & \multicolumn{1}{|c|}{ INDÚSTRIA } & \multicolumn{1}{c|}{ COMÉRCIO E SERVIÇOS } \\
\hline Microempresa & Até 19 & Até 9 \\
\hline $\begin{array}{l}\text { Empresas de } \\
\text { Pequeno Porte }\end{array}$ & De 20 a 99 & De 10 a 49 \\
\hline Médias empresas & De 100 a 499 & De 50 a 99 \\
\hline Grandes empresas & Mais de 500 empregados & Mais de 100 empregados \\
\hline
\end{tabular}

QUADRO 1 - Critério de classificação do porte da empresa por número de empregados Fonte: SEBRAE (2012).

Henschel (2009) destaca que essa distinção na classificação das empresas se dá por considerar que uma gama de empresas não demonstra uma estrutura homogênea como, por exemplo, o conhecimento de todos os métodos de gestão e os critérios utilizados para a tomada de decisão. O autor destaca que o número de funcionários é usualmente utilizado como um critério de classificação por diversos pesquisadores. As pequenas e médias empresas demonstram uma contribuição fundamental para a economia em termos de emprego, inovação e crescimento. Essas empresas geralmente utilizam métodos menos burocráticos e com maior flexibilidade de gestão. É relevante destacar que nessas organizações há, muitas vezes, a presença familiar no controle, com pouca especialização, sendo capazes de realizar várias funções (TURNER; LEDWITH; KELLY, 2010).

Assim, as pequenas empresas geralmente são administradas por seus proprietários, apresentam quadro reduzido de funcionários, não há uma domínio do mercado em que atuam, não possuem recursos financeiros elevados e o valor do capital e faturamento anual geralmente são reduzidos (BATISTA et al., 2012). Ao considerar que a gestão das micro e pequenas empresas é fortemente influenciada

FERNANDES, F. C.; WRUBEL , F.; DALLABONA, L. F. Gerenciamento de riscos na cadeia de suprimentos de micro e pequenas empresas têxteis: discussão exploratória sobre oportunidades de pesquisa. Revista de Empreendedorismo e Gestão de Pequenas 
pelo perfil pessoal e capacidade administrativa dos proprietários, é relevante que estes pratiquem o desenvolvimento de habilidades e competências empreendedoras para proporcionar eficiente administração e continuidade das atividades da empresa.

Moraes e Escrivão Filho (2006) esclarecem que é relevante a análise minuciosa das características de pequenas empresas para compreender melhor seus processos decisórios, sendo possível propor medidas eficazes para reduzir as dificuldades encontradas e auxiliar na sua continuidade. Para Harland, Brenchley e Walker (2003), as atitudes que envolvem riscos são influenciadas pela natureza da atividade, estilo individual e comportamento do administrador, sendo relevante o estudo dos riscos de suas atividades.

$\mathrm{Na}$ concepção de Harland, Brenchley e Walker (2003), antigamente, as empresas adquiriam matéria-prima e vendiam seus produtos diretamente ao cliente, sem ter uma rede de abastecimento complexa. Nesse processo, o risco era menos difundido. Porém, com o aumento da complexidade de produtos e/ou serviços e redes de abastecimento em fronteiras internacionais, os riscos aumentaram e os locais que se identificam tais riscos se alteraram, justamente em função das mudanças complexas nas redes de abastecimento.

Dessa forma, é relevante as micro e pequenas empresas utilizarem mecanismos de controle e gerenciamento de riscos inerentes aos negócios, haja vista que sem controle específico das atividades pertinentes à sua cadeia de suprimentos e logística podem acarretar problemas sérios e, consequentemente, o declínio de suas atividades operacionais.

\section{Riscos e gerenciamento de riscos}

Para o Committee of Sponsoring Organizations of the Treadwaycommission (COSO) (2004, p. 04), o gerenciamento de riscos é o:

[...] processo conduzido em uma organização pelo conselho de administração, diretoria e demais empregados, aplicado no estabelecimento de estratégias, formuladas para identificar em toda a organização, eventos em potencial capazes de afetá-la, e administrar os riscos [...].

FERNANDES, F. C.; WRUBEL , F.; DALLABONA, L. F. Gerenciamento de riscos na cadeia de suprimentos de micro e pequenas empresas têxteis: discussão exploratória sobre oportunidades de pesquisa. Revista de Empreendedorismo e Gestão de Pequenas 
Além da administração dos riscos, o documento relata que é necessário "mantê-los compatíveis com o apetite a risco da organização e possibilitar garantia razoável do cumprimento dos seus objetivos" (COSO, 2004, p. 04).

O cOSO (Committee of Sponsoring Organizations of the Treadway Comission - Comitê das Organizações Patrocinadoras) é uma entidade sem fins lucrativos que se dedica à melhoria contínua dos relatórios financeiros, principalmente no que tange aos controles internos e gerenciamento de riscos corporativos. Em 1992, publicou um protocolo intitulado por "The COSO Report", sugerindo cinco componentes essenciais que envolvem o controle interno das organizações, sendo: ambiente de controle, avaliação de riscos, atividades de controle, informação e comunicação. Desde então, o COSO Report passou a ser referência mundial no que diz respeito aos controles internos.

Porém, diante dos escândalos empresariais que ocasionaram perdas por parte de investidores e acionistas, o COSO emitiu um novo documento em 2004 intitulado por COSO ERM (Enterprise Risk Management Integrated Framework). Tal documento foi elaborado de acordo com as premissas do COSO Report, apresentando os componentes essenciais, princípios e conceitos para o gerenciamento de riscos corporativos.

Guimarães (2006, p. 32) destaca que os "riscos podem possuir diferentes conotações, como as de ordem física, estrutural, econômica, social e ambiental, desdobrando-se em diversos componentes e em sucessivos níveis de detalhamento", o que necessita, portanto, de gerenciamento. Esse gerenciamento é amplamente abordado pelo COSO (2004), sendo que a ampliação do COSO Report para o COSO ERM proporcionou às organizações, maior complexidade quanto ao controle interno para gerenciar os riscos inerentes ao negócio.

O risco e a incerteza são a prova de que o campo está sempre ampliando e as práticas, processos, conceitos e teorias devem expandir-se com ele (CAVINATO, 2004). Assim, as pesquisas sobre o tema também tendem a intensificarem-se. No cenário brasileiro, Mattos (2011) pesquisou as atitudes e comportamentos sobre a gestão de riscos em cadeias de suprimentos e concluiu que os principais aspectos relativos aos riscos adotados pelas empresas no Brasil estão voltados para a reação

FERNANDES, F. C.; WRUBEL , F.; DALLABONA, L. F. Gerenciamento de riscos na cadeia de suprimentos de micro e pequenas empresas têxteis: discussão exploratória sobre oportunidades de pesquisa. Revista de Empreendedorismo e Gestão de Pequenas 
a eventos e que existe uma forte tendência dos gestores a direcionarem mais esforços em ações reativas do que em medidas de contenção.

\section{Cadeia de suprimentos e cadeia logística}

A logística apresenta contínua evolução desde a Segunda Guerra Mundial, sendo considerada elemento fundamental na formulação das estratégias das organizações. Ballou (2006) destaca que a logística trata da criação de valor - para os clientes e fornecedores e todos aqueles que têm interesses diretos nela. $\mathrm{O}$ seu valor manifesta-se primariamente em termos de tempo e lugar. Produtos e serviços não têm valor a menos que estejam em poder do cliente quando (tempo) e onde (lugar) eles pretenderem consumi-los.

No processo logístico, o gerenciamento de riscos envolve ações tomadas pela organização para melhorar a sua posição de risco, sendo que atitudes da organização em relação ao risco irão afetar o seu sistema de desempenho e moldar como indivíduos dentro da organização reagirão aos acontecimentos (OLSON, WU, 2010). Para que os sistemas logísticos sejam eficazes, contingências de riscos devem ser identificadas, mitigadas e monitoradas. Ao concluir que os riscos são prováveis futuras perdas é importante tratar sobre custos logísticos, que são fatores críticos na cadeia de suprimentos em um país com as dimensões geográficas e a infraestrutura como o Brasil.

O correto planejamento logístico (sistema de suprimento e distribuição) deve estar baseado nos custos logísticos diretos, em considerações de nível de serviço, responsabilidades legais e contingências (BALLOU, 1993). O nível de serviço logístico é "a qualidade com que fluxo de bens e serviços é gerenciado. É o resultado líquido de todos os esforços logísticos da firma" (BALLOU, 1993, p. 73).

Para que a empresa atinja seus objetivos não é suficiente que visualize apenas as operações internas, isoladamente, embora isso seja útil para integrar todas as funções, atividades e tarefas (BOWERSOX; CLOSS, 1996). É necessário, conforme autores, que estendam seu comportamento para incorporar clientes e 
fornecedores por meio da integração externa, denominada gestão da cadeia de suprimentos.

Para Tummala e Schoenherr (2011), os gestores devem planejar interrupções e desenvolver planos de contingência como projetar ou redesenhar suas cadeias de suprimentos, interdependências da cadeia de suprimentos, identificar potenciais fatores de risco, sua probabilidade, consequências e gravidades, sendo que o plano de ação de gestão de risco pode, então, ser desenvolvido para evitar a preferência dos riscos identificados ou, se não for possível, pelo menos atenuar, conter e controlar.

\section{Aspectos metodológicos}

Desenvolveu-se uma pesquisa exploratória e qualitativa com multicasos. Ela é conduzida por entrevistas semiestruturadas. Caracteriza-se como exploratória por considerar que por meio desses estudos "busca-se conhecer com maior profundidade o assunto, de modo a torná-lo mais claro ou construir questões importantes para a condução da pesquisa". De acordo com os referidos autores, "explorar um assunto significa reunir mais conhecimento e incorporar características inéditas, bem como buscar novas dimensões até então não conhecidas" (RAUPP; BEUREN, 2006, p. 80).

Diante do contexto, a pesquisa caracteriza-se como exploratória, pois analisa riscos e mecanismos de gerenciamento em relação à cadeia de suprimentos/logística de micro e pequenas empresas com enfoque para futuras pesquisas, envolvendo os resultados empíricos de empresas sediadas em Blumenau/SC que industrializam produtos para a cadeia têxtil.

Como universo populacional, definiram-se as empresas associadas à Associação das Microempresas, Empresas de Pequeno Porte e Empreendedores Individuais (AMPE) de Blumenau/SC. Considerando a representatividade do segmento de pequenos negócios, justifica-se a escolha por essas empresas considerando a disponibilidade dos contatos delas no website da AMPE, o que possibilita o acesso a elas.

FERNANDES, F. C.; WRUBEL , F.; DALLABONA, L. F. Gerenciamento de riscos na cadeia de suprimentos de micro e pequenas empresas têxteis: discussão exploratória sobre oportunidades de pesquisa. Revista de Empreendedorismo e Gestão de Pequenas 
Ao considerar que o objetivo do estudo está relacionado à cadeia de suprimentos e logística, pressupõe-se que as indústrias caracterizam com melhor precisão as empresas objeto de estudo, por apresentarem um processo mais complexo como, por exemplo, obter matérias-primas, processos de industrialização e entrega dos produtos. Dessa forma, para a estratificação da amostra, optou-se em analisar as micro e pequenas empresas categorizadas pela AMPE como indústrias. Inicialmente, identificaram-se 105 indústrias das diversas categorias econômicas filiadas à AMPE.

Blumenau/SC pertence à região do médio vale do Itajaí e a atividade econômica de Indústria da Transformação (Fabricação de produtos têxteis e Confecção de artigos de vestuário e acessórios) representou $23 \%$ do Valor Adicionado Fiscal em 2007, sendo estas as atividades com maiores percentuais no ano (SEBRAE, 2010). Essa região do estado possui o menor montante de municípios subdesenvolvidos (nenhum município subdesenvolvido, 29\% desenvolvidos e 71\% estão em desenvolvimento) segundo Raiher (2013). Esses dados são obtidos pela subdivisão dos Índices de Desenvolvimento Humano do Estado do ano de 2000, divididos em três categorias: subdesenvolvido, em desenvolvimento e desenvolvido.

Como essa região sedia um polo têxtil de alto impacto, optou-se, de forma intencional, analisar as indústrias que desenvolvem produtos para esse ramo de atividade. Dessa forma, inicialmente manteve-se contato por telefone, e-mail e pessoalmente com os responsáveis pelas oito indústrias para agendamento das entrevistas. Três empresas foram excluídas da amostra por não ter acesso pelos meios de comunicação e/ou não ter feedback dos proprietários. Assim, a amostra compreende cinco indústrias de equipamentos têxteis que concederam entrevista.

Para a coleta de dados, estruturou-se um roteiro de entrevista com questões que envolveram os oito componentes do COSO (2004), com enfoque para a cadeia de suprimentos e logística. Também foram utilizados os estudos de Peck (2003), Juttner, Peck e Christopher (2003), Blos, Wee e Watanabe (2009), que tiveram o objetivo de analisar os riscos $e$ as vulnerabilidades na cadeia de suprimento/logística. Para análise dos dados, foi utilizada a técnica de análise de 
conteúdo. Para a validação do instrumento de pesquisa, aplicou-se a entrevista em uma microempresa sediada em Indaial/SC. Após a entrevista, foram necessários ajustes quanto a sequência de questionamentos, considerando que em determinados momentos da entrevista, os temas se repetiam. As entrevistas ocorreram no mês de abril de 2013 e todas foram transcritas na íntegra.

Como a pesquisa envolve estudos multicasos com aplicação de entrevista semiestruturada, destaca-se como limitação, o instrumento de coleta de dados, ao considerar que os respondentes podem, no transcorrer da entrevista, omitir informações relevantes por não interpretar os questionamentos dos entrevistadores ou por não se lembrar, naquele momento, de algum aspecto relevante sobre os riscos inerentes aos negócios.

\section{Descrição e análise dos dados}

Essa seção descreve os estudos multicasos e relata características gerais dos entrevistados e indústrias, processos da cadeia de suprimentos/logística, riscos internos e externos inerentes aos processos logísticos e suprimentos, e o gerenciamento por meio do COSO/ERM. Apresentam-se discussões e sugestões de exploração de pesquisas referente a relações necessárias, explicações e possíveis correlações dos achados dessa pesquisa.

\section{Características gerais dos entrevistados e indústrias}

Quanto às características dos entrevistados, constata-se que, com exceção de um participante com curso técnico, todos são diplomados com cursos de graduação. No que se refere ao tempo de atuação, dois entrevistados atuam há menos de 5 anos na indústria, dois entre 5 e 10 anos e 1 participa das atividades da empresa há mais de 33 anos. As principais funções desempenhadas são: planejamento e controle da produção (PCP), gerente financeiro, empresário e gerente de produção.

FERNANDES, F. C.; WRUBEL , F.; DALLABONA, L. F. Gerenciamento de riscos na cadeia de suprimentos de micro e pequenas empresas têxteis: discussão exploratória sobre oportunidades de pesquisa. Revista de Empreendedorismo e Gestão de Pequenas 
As atividades industriais das empresas analisadas estão diretamente relacionadas ao setor têxtil da região de Blumenau/SC, pois fabricam produtos específicos para esse ramo de atividade, como a Indústria "A" que se destina à gravação em cilindros, a Indústria "B" fabrica quadros, a "C" desenvolve matrizes para estamparias com gravações em quadros ou cilindros, a "D" concentra suas atividades operacionais na fabricação de peças para confecções e a "E" industrializa máquinas para camisaria e comercializa peças diversas. Apresentam-se mais detalhes no quadro 2:

\begin{tabular}{|l|c|c|c|c|c|}
\hline Características gerais & Ind. A & Ind. B & Ind. C & Ind. D & Ind. E \\
\hline $\begin{array}{l}\text { Tempo de atuação no } \\
\text { mercado }\end{array}$ & 20 anos & 21 anos & 33 anos & 35 anos & 8 anos \\
\hline Possui filiais & Não & Não & Não & Não & Não \\
\hline N. de Funcionários & 44 & 26 & 30 & 21 & 8 \\
\hline $\begin{array}{l}\text { Area de atuação } \\
\text { (atacado/varejo) }\end{array}$ & $\begin{array}{c}\text { Atacado/ } \\
\text { varejo }\end{array}$ & Atacado & Atacado & $\begin{array}{c}\text { Atacado/ } \\
\text { varejo }\end{array}$ & $\begin{array}{c}\text { Atacado/ } \\
\text { varejo }\end{array}$ \\
\hline $\begin{array}{l}\text { Estados de atuação no } \\
\text { Brasil }\end{array}$ & $\begin{array}{c}\text { SC/SP/PR } \\
\text { /RS }\end{array}$ & SC & SC & $\begin{array}{c}\text { SC/PR/R } \\
\text { S/RN }\end{array}$ & $\begin{array}{c}\text { SC/MG/SP/ } \\
\text { RJ/PR/RS }\end{array}$ \\
\hline Importa/exporta & Sim & Não & Não & Não & Não \\
\hline $\begin{array}{l}\text { Utiliza sistemas } \\
\text { informatizados }\end{array}$ & Sim & Não & Sim & Sim & Sim \\
\hline
\end{tabular}

QUADRO 2 - Características gerais das indústrias

Fonte: dados da pesquisa.

Destaca-se que a Indústria "A" é a única que importa uma parte da matériaprima da Austrália, porém não exporta e a "C" já importou mercadoria. A média geral de atuação no mercado é de 23,4 anos. Conforme dados dispostos no quadro 1 , a indústria "E" classifica-se como microempresa e as demais como pequenas empresas, conforme sugere o IBGE. O número de funcionários é utilizado por muitos pesquisadores para caracterizar o porte das empresas (HENSCHEL, 2009). As pequenas empresas contribuem substancialmente para a economia, emprego, inovação e crescimento, utilizando métodos menos burocráticos e com flexibilidade de gerenciamento, considerando que muitas vezes são administradas por familiares (TURNER; LEDWITH; KELLY, 2010).

Quanto aos sistemas informatizados, uma empresa não utiliza tal mecanismo. Essa indústria destacou que já houve análise para implementação de sistemas informatizados, porém "como o processo é tão dinâmico [...] é tão rápido [...] vai ter 
horas que [...] vai se perder as informações [...] teria que ter uma pessoa só pra controlar isso". Já as empresas que utilizam sistemas informatizados, as principais informações geradas estão relacionadas às ordens de compra e controle de estoques (MRP). É relevante destacar que apenas duas das indústrias pesquisadas expandem seus produtos para outras regiões geográficas como, São Paulo, Paraná, Rio Grande do Sul, Nordeste, Minas Gerais, Rio de Janeiro, etc. As demais atuam principalmente na região sul do Brasil.

\section{Processos da cadeia de suprimentos/logística das indústrias}

Os principais processos da cadeia de suprimentos e logística das empresas multicasos envolvem: compra de matéria-prima; transporte da matéria-prima até a indústria; movimentação interna dos materiais e produtos; armazenamento da matéria-prima; estocagem dos produtos acabados, vendas e entrega dos produtos aos clientes. Os processos identificados serão mencionados no Quadro 03.

\section{PROCESSO DE COMPRA DE MATÉRIA-PRIMA}

Realizado pela indústria "A": o pedido ao fornecedor é feito especificamente para a empresa. A matéria-prima (MP) principal é o níquel, que é importada, isso acontece em cerca de $30 \%$ das compras, ou adquirida do estado de São Paulo. As principais MP adquiridas são o níquel para os cilindros e os anéis que serão utilizados na estamparia. As demais indústrias ("B", "C", "D" e "E") não utilizam processo de importação da MP, diminuindo a complexidade do processo de aquisição, sendo que as indústrias "B", "C" e "E" adquirem de fornecedor importador. Os principais fornecedores localizam-se na região sul ou no estado de São Paulo e as suas principais MP são: poliéster, madeiras e produtos químicos (Indústria "B"), ferro, alumínio, tecido e produtos químicos ("C"), inox ("D") e ferro e metais ("E"). Na indústria "C" o processo de compra inicia pelo pedido ao fornecedor, que ocorrem conforme consumos ou necessidade. A MP utilizada pela "D" tem um único produtor no Brasil, sendo que as compras são feitas diretamente deste ou de revendedores, dependendo das condições de entrega e prazo, pois o preço não irá ter grandes oscilações entre os fornecedores. Um processo mencionado pela "E" é o fato de utilizar-se também de algumas peças terceirizadas em outra cidade da região, nesse caso, as compras são feitas e a entrega é realizada diretamente para a terceirizada ou na própria indústria, que envia posteriormente para a industrialização. A pintura da máquina, em alguns casos, também é terceirizada.

$$
\text { PROCESSO DE TRANSPORTE DA MATÉRIA-PRIMA ATÉ AS INDÚSTRIAS }
$$

Realizado por transportadoras e fica por conta da indústria ou do fornecedor, pois depende da negociação. O preço do frete também é negociado. Destaca-se que a indústria "A" importa da Austrália, portanto, terá um processo diferenciado de transporte, além disso, para essa empresa o transporte é feito especificamente para a carga solicitada que, conforme entrevista, menciona: "o transporte é feito única e exclusivamente pra aquela carga, não vem outra carga junto", por considerar que a MP é frágil.

continua....

FERNANDES, F. C.; WRUBEL , F.; DALLABONA, L. F. Gerenciamento de riscos na cadeia de suprimentos de micro e pequenas empresas têxteis: discussão exploratória sobre oportunidades de pesquisa. Revista de Empreendedorismo e Gestão de Pequenas Empresas, v.4, n. 1, 2015. 
continuação....

\section{PROCESSO DE MOVIMENTAÇÃO INTERNA DOS MATERIAIS}

$\mathrm{Na}$ indústria "A": quando os cilindros chegam são retirados das caixas e sofrerão diversos processos, dependendo da máquina, ou seja, pode ser arredondamento, processo com cera, emulsão, etc. Destaca-se nesta indústria que esses cilindros necessitam de cuidados "[...] eles são colocados num depósito onde precisa ter um identificador pra que eles estejam sempre na mesma temperatura e sem umidade, porque eles estragam". Os processos das demais indústrias ("B" e "E") são semelhantes, sendo que, na indústria "C" a MP fica armazenada em depósito e o pessoal que a conhece, retira-a deste depósito para iniciar o processo de gravação, conforme ordens de produção emitidas pelo sistema. A indústria "D" recebe a MP em bobinas e chapas e a utiliza conforme a necessidade.

\section{PROCESSO DE ESTOCAGEM DE PRODUTOS ACABADOS}

Na indústria " $A$ " o processo é de menos de 24 horas. O processo também é dinâmico na indústria "C" e "B", pois existe essa necessidade, em função do tipo de produto produzido. Na indústria "D", o estoque acabado é armazenado em depósito específico em gavetas ou cestinhas. Na indústria "E" os produtos acabados também não ficam por muito tempo estocados e são produzidos conforme pedido do cliente, portanto, logo após as máquinas produzidas estarem acabadas. Estas são enviadas aos clientes.

$$
\text { PROCESSO DE VENDA E ENTREGA DOS PRODUTOS AOS CLIENTES }
$$

A indústria "A" tem um vendedor externo. As vendas concentram-se para clientes fidelizados, mas em todas as indústrias os clientes também procuram diretamente a empresa. As indústrias "A", "B" e "C" possuem departamentos de arte ou desenho que oferecem opções de desenhos de estampas para os clientes. A "D" possui venda das peças no balcão, mas também faz entregas aos revendedores. A "E" possui diversos representantes no Brasil e a entrega das máquinas produzidas é feita, na maior parte, de maneira montada. Em todas as indústrias, o processo é feito por frotas próprias quando o cliente é de Blumenau ou região e por transportadora para os demais estados. Não possuem Centro de Distribuição.

QUADRO 3 - Principais processos da cadeia de suprimentos/logística

Fonte: dados da pesquisa.

Quanto às futuras pesquisas, algumas específicas sobre rotas, programação de entrega, manutenção da frota e gestão de riscos, poderiam ser realizadas em empresas que utilizam transporte com frota própria. O processo de exportação pode ter mais riscos por ser mais complexo, entretanto, essa é uma lacuna de pesquisa que pode ser explorada para empresas de micro e pequeno porte, visando analisar custos/benefícios da operação. Pode-se ainda, quantificar atividades de terceirização nas micro e pequenas empresas, inclusive analisando casos que utilizem alianças corporativas estratégicas ou redes de cooperação com foco na influência dessas combinações na gestão da cadeia logística/suprimentos.

As indústrias pesquisadas, em sua maioria, atendem o polo de indústrias têxteis de SC com seus produtos e equipamentos. $\mathrm{O}$ fato de estarem inseridas em um polo têxtil instiga pesquisas sobre a influência desse polo nas suas atividades. Da mesma forma, estudos poderiam ser realizados sobre os benefícios e desafios

FERNANDES, F. C.; WRUBEL , F.; DALLABONA, L. F. Gerenciamento de riscos na cadeia de suprimentos de micro e pequenas empresas têxteis: discussão exploratória sobre oportunidades de pesquisa. Revista de Empreendedorismo e Gestão de Pequenas Empresas, v.4, n. 1, 2015. 
de operacionalização e atuação das micro e pequenas empresas quanto às suas cadeias logística/suprimentos quando inseridas em polos industriais (calçadista, petroquímico, entre outros).

Dentre os processos mencionados pelos entrevistados é relevante destacar a importância do planejamento e controle de toda cadeia de suprimentos e logística ao considerar que os profissionais envolvidos precisam, de acordo com Ballou (2006), estarem preparados e ter competência para controlar circunstâncias extraordinárias que porventura venham interromper o sistema produtivo e operacional das indústrias.

\section{Riscos inerentes à cadeia de suprimentos/logística}

O COSO (2004) especifica, dentre os oito componentes, que as empresas precisam definir os objetivos e identificar os eventos relacionados aos riscos. 0 primeiro referencia que todos os objetivos precisam estar predefinidos para que a gerência possa identificar e gerenciá-los. O segundo refere-se à identificação dos riscos tanto internos (movimentação de matéria-prima, controle de estoques, atividades e competências de funcionários, etc.) quanto externos (entregas de mercadorias, relação com clientes, fornecedores, etc.). Dessa forma, apresenta-se no Quadro 4 os principais riscos identificados. 


\begin{tabular}{|l|l|}
\hline INDÚSTRIA & \multicolumn{1}{|c|}{ RISCOS IDENTIFICADOS } \\
\hline Indústria "A" & $\begin{array}{l}\text { (a) compras realizadas especificamente para a indústria; (b) transporte } \\
\text { específico; (c) manuseio da matéria prima (MP) (cilindro) no transporte } \\
\text { até a indústria; (d) cuidados de iluminação, temperatura e umidade no } \\
\text { depósito de MP. Outros riscos, que envolvem a MP principal: (e) } \\
\text { manuseio dentro da indústria, (f) escolha do fornecedor na busca por } \\
\text { qualidade; (g) processos mais complexos de importações. No processo } \\
\text { de entrega dos produtos para o cliente existe o risco de (h) manuseio do } \\
\text { produto pronto e (i) transporte do produto pronto até o cliente. A indústria } \\
\text { também mencionou possuir riscos de perdas no processo produtivo. }\end{array}$ \\
\hline Indústria "B" & $\begin{array}{l}\text { (a) aquisição de matéria prima de fornecedor importador; (b) manuseio } \\
\text { de matérias primas, que são produtos químicos, foi apontado como um } \\
\text { risco para essa indústria; (c) pouco conhecimento de clientes sobre } \\
\text { processos; (d) prazos de entrega dos produtos. }\end{array}$ \\
\hline Indústria "C" & $\begin{array}{l}\text { (a) risco no manuseio das matérias primas no transporte; (b) manuseio } \\
\text { de matérias primas que são produtos químicos e (c) escolha do } \\
\text { fornecedor na busca por qualidade. }\end{array}$ \\
\hline Indústria "D" & $\begin{array}{l}\text { (a) manuseio da MP dentro da indústria (b) softwares para controle de } \\
\text { estoques de produtos prontos, (c) manuseio do produto pronto, (d) } \\
\text { transporte do produto pronto até o cliente, (e) sazonalidade da quantidade } \\
\text { de vendas. Perdas no processo produtivo. }\end{array}$ \\
\hline Indústria "E" & $\begin{array}{l}\text { (a) competências dos funcionários, (b) riscos da empresa terceirizada não } \\
\text { atender o projeto adequado das peças; (b) riscos na programação de } \\
\text { entrega das partes terceirizadas, (i) transporte do produto pronto até o } \\
\text { cliente. }\end{array}$ \\
\hline
\end{tabular}

QUADRO 4 - Principais riscos identificados na cadeia de suprimentos/logística das indústrias Fonte: dados da pesquisa.

Os gestores das indústrias preocupam-se com a quantidade e qualidade de matéria-prima que é solicitada nas compras e com o prazo de entrega dos seus produtos. Com base nas informações sobre riscos encontradas, acredita-se ser importante a realização de pesquisas quantitativas dos riscos e sobre o impacto que os riscos da cadeia de logística/suprimentos possuem no resultado global. As empresas dos multicasos têm representatividade econômica na região estudada, assim como as micro e pequenas empresas de modo geral têm representatividade econômica no Brasil.

Portanto, o estudo sugerido torna-se justificável e poderá trazer oportunidades de ganhos econômicos com o conhecimento e mensuração dos riscos dessa cadeia para esse tipo de categoria econômica. No decorrer dessa análise, apresentam-se outras oportunidades de futuras pesquisas com o mesmo foco.

As pesquisas futuras poderiam investigar as principais dificuldades identificadas por micro e pequenas empresas de diferentes setores econômicos quanto ao gerenciamento dos riscos, no que se refere aos aspectos internos e

FERNANDES, F. C.; WRUBEL , F.; DALLABONA, L. F. Gerenciamento de riscos na cadeia de suprimentos de micro e pequenas empresas têxteis: discussão exploratória sobre oportunidades de pesquisa. Revista de Empreendedorismo e Gestão de Pequenas Empresas, v.4, n. 1, 2015. 
externos do mercado em que atuam como, por exemplo, instabilidade de mercado (dependendo do setor em que atua), oscilações nas taxas de câmbio (quando importam ou exportam), concorrência (preços), qualidade dos produtos (quanto à concorrentes e diferentes fornecedores), etc.

\section{Monitoramento e mecanismos de mitigação e prevenção de riscos na cadeia de suprimentos/logística}

Os riscos que abrangiam todas as indústrias estudadas foram detectados nos discursos e construiu-se o quadro 5 que destaca o resumo dos principais riscos e mitigação quanto a cadeia de suprimentos e logística identificados. Posteriormente, exploram-se ideias para o desenvolvimento de futuras pesquisas.

Quanto ao risco de liquidez/capital de giro e padrão de crédito (Quadro 5), constata-se que as indústrias divulgam pouco sobre quais seriam as formas de mitigação utilizadas. Estudos futuros para identificar formas de mitigação dos riscos em relação a esses aspectos (liquidez/capital de giro, padrões de créditos) são relevantes para explicar as vulnerabilidades. 


\begin{tabular}{|c|c|}
\hline PRINCIPAIS RISCOS & MECANISMOS DE MITIGAÇÃO \\
\hline $\begin{array}{l}\text { Quando comprar } \\
\text { matéria prima }\end{array}$ & $\begin{array}{l}\text { Planejamento por gestores experientes, com base em controle } \\
\text { dos pedidos ou histórico de programações. }\end{array}$ \\
\hline $\begin{array}{l}\text { Como comprar matéria } \\
\text { prima }\end{array}$ & $\begin{array}{l}\text { Considerar negociação de preço, mas principalmente, a } \\
\text { qualidade da matéria prima. Buscar fidelidade e parceria do } \\
\text { fornecedor. }\end{array}$ \\
\hline $\begin{array}{l}\text { Importação } \\
\text { matéria-prima }\end{array}$ & $\begin{array}{l}\text { Planejamento com antecedência e por pessoal com experiência. } \\
\text { Utilização de serviços de empresa específica para fazer } \\
\text { despacho aduaneiro, alfandegário e de portos. Programar-se para } \\
\text { testar matérias-primas (MP) alternativas caso atrase o sistema } \\
\text { portuário, assim como reinventar os produtos para utilizar MP } \\
\text { disponíveis e que satisfizessem o cliente. }\end{array}$ \\
\hline $\begin{array}{lr}\text { Manuseio } & e \\
\text { acondicionamento de } \\
\text { matérias primas }\end{array}$ & $\begin{array}{l}\text { Matéria prima (produto químico): Utilização de EPIs e treinamento } \\
\text { de funcionários. Matéria prima frágil: Treinamento de funcionários } \\
\text { para manuseio e acondicionamento adequado. Monitoramento do } \\
\text { supervisor. }\end{array}$ \\
\hline $\begin{array}{l}\text { Entrega } \\
\text { mercadorias } \\
\text { produtos }\end{array}$ & Planejamento das compras e produção para atender aos clientes. \\
\hline $\begin{array}{l}\text { Transporte próprio das } \\
\text { mercadorias/produtos }\end{array}$ & $\begin{array}{l}\text { Utilização de funcionários treinados para a função e que } \\
\text { conhecem os riscos do manuseio inadequado para a entrega. }\end{array}$ \\
\hline Funcionários & Treinamento e utilização de EPIs. \\
\hline $\begin{array}{l}\text { Liquidez/capital de giro } \\
\text { e padrão de crédito }\end{array}$ & Política de baixa estocagem. \\
\hline $\begin{array}{l}\text { Regulamento do } \\
\text { governo }\end{array}$ & $\begin{array}{l}\text { Mensurar os custos das regulamentações e considerá-las nos } \\
\text { orçamentos e preço de venda. }\end{array}$ \\
\hline Tecnologia & $\begin{array}{l}\text { Os investimentos em máquinas são planejados para } \\
\text { acontecerem. Na indústria de máquinas são terceirizados alguns } \\
\text { processos pelo fato que a tecnologia necessária para o referido } \\
\text { exigiria grandes investimentos. }\end{array}$ \\
\hline
\end{tabular}

QUADRO 5 - Principais riscos e mitigação de riscos da cadeia de suprimentos/logística

Fonte: dados da pesquisa.

Verificou-se que os mecanismos utilizados para os riscos mais apontados são adequados, entretanto, a mitigação destes será eficiente se os gestores fizerem planejamentos das atividades e necessidades, assim como utilizarem indicadores e acompanhamentos dessas atividades (compra de matéria-prima, importação, capital de giro e investimentos em tecnologia). É possível sugerir pesquisas que objetivem elaborar, eleger e quantificar indicadores de desempenho logístico/suprimentos nas micro e pequenas empresas.

Algumas indústrias pesquisadas contam com uma estrutura familiar no comando e os membros da família são capazes de executar várias funções na indústria. Isso ocorre conforme sugere Turner, Ledwith e Kelly (2010) para micro e pequenas empresas. Outra característica dessas indústrias pesquisadas é que

FERNANDES, F. C.; WRUBEL , F.; DALLABONA, L. F. Gerenciamento de riscos na cadeia de suprimentos de micro e pequenas empresas têxteis: discussão exploratória sobre oportunidades de pesquisa. Revista de Empreendedorismo e Gestão de Pequenas Empresas, v.4, n. 1, 2015. 
apresentam ter um quadro reduzido de funcionários, sendo característico de pequenas empresas (BATISTA et al., 2012).

Para mitigar eventuais riscos inerentes à cadeia de suprimentos e logística, as empresas contratam seguros dos mais variados como, por exemplo, seguros de carga (transporte) da matéria-prima e produto acabado, como citam os entrevistados das indústrias "A" e "E". Ballou (2006) menciona que a contratação de seguros é tida como possíveis formas de reduzir ou evitar rupturas súbitas na cadeia de suprimentos. As demais empresas possuem seguros de imóveis, veículos próprios e seguros contra incêndios, raios e vendavais.

A atuação e realidade das micro e pequenas indústrias pesquisadas nos oito componentes está descrita no Quadro 06. 


\begin{tabular}{|c|c|}
\hline COMPONENTES & ITENS IDENTIFICADOS POR COMPONENTE \\
\hline Ambiente interno & $\begin{array}{l}\text { As indústrias possuem em média } 23 \text { anos de atuação e na sua } \\
\text { maioria, o ambiente de gestão é familiar. Os proprietários pertencem e } \\
\text { participam ativamente da gestão da indústria, sendo que os riscos são } \\
\text { identificados e dirigidos conforme perfil e valores desses. }\end{array}$ \\
\hline $\begin{array}{l}\text { Definição dos } \\
\text { objetivos }\end{array}$ & $\begin{array}{l}\text { A experiência dos gestores é utilizada na definição dos objetivos, } \\
\text { assim como, os mesmos procuram fazer planejamentos. }\end{array}$ \\
\hline $\begin{array}{l}\text { Identificação de } \\
\text { eventos }\end{array}$ & $\begin{array}{l}\text { A experiência dos gestores é utilizada na identificação de eventos } \\
\text { potenciais que afetam a realização dos objetivos, o planejamento é } \\
\text { realizado na identificação de eventos internos e externos que afetam a } \\
\text { realização dos objetivos das indústrias e representem riscos ou } \\
\text { oportunidades: concorrentes e escolha de fornecedores (eventos } \\
\text { externos); pessoal, processos, compras importadas, prazos de entrega } \\
\text { de produtos e tecnologia utilizada (fatores internos). Entretanto, fatores } \\
\text { externos econômicos e políticos são apenas identificados conforme } \\
\text { acontecem e os eventos internos de pedidos de compra são } \\
\text { realizados conforme necessidade da produção ou surgimento das } \\
\text { vendas, o que pode fazer com que a empresa necessite agir } \\
\text { rapidamente e em força-tarefa para satisfazer seus clientes caso } \\
\text { algum problema no processo aconteça. }\end{array}$ \\
\hline Avaliação do risco & $\begin{array}{l}\text { Os riscos planejados são identificados e analisados formalmente, } \\
\text { entretanto, riscos não planejados ou imprevistos (principalmente } \\
\text { externos) são identificados informalmente e gerenciados conforme } \\
\text { prioridades eleitas pelos proprietários. }\end{array}$ \\
\hline Resposta ao risco & $\begin{array}{l}\text { A gestão identifica e avalia possíveis respostas aos riscos, evitando, } \\
\text { aceitando, reduzindo e compartilhando o risco. }\end{array}$ \\
\hline $\begin{array}{l}\text { Atividades } \\
\text { controle }\end{array}$ & $\begin{array}{l}\text { Políticas e procedimentos são estabelecidos pelos proprietários para } \\
\text { ajudar a garantir as respostas aos riscos efetivamente realizados. A } \\
\text { empresa possui controles formais das solicitações de compras, } \\
\text { pedidos e entregas dos clientes e ordens de produção. Muitos } \\
\text { controles e supervisões são realizados pelos proprietários ou seus } \\
\text { membros da família. }\end{array}$ \\
\hline $\begin{array}{l}\text { Informação } \\
\text { comunicação }\end{array}$ & $\begin{array}{l}\text { As empresas tem ambiente de fluxo de processos atendidos por fichas } \\
\text { de controle e gerido por pessoal do setor de PCP. Este ambiente é } \\
\text { menos complexo do que o de grandes empresas. Informações } \\
\text { relevantes para identificação e gerenciamento de riscos que possam } \\
\text { ser capturadas e comunicadas e que permitam às pessoas cumprir } \\
\text { suas responsabilidades poderiam ser mais adequadas se as indústrias } \\
\text { possuíssem sistemas de informação que atendessem eficazmente } \\
\text { suas necessidades, principalmente quanto ao controle de estoques. }\end{array}$ \\
\hline Monitoramento & $\begin{array}{l}\text { As atividades de monitoramento contínuo concentram-se em identificar } \\
\text { necessidades de compras de matéria prima, rotinas de processos de } \\
\text { entregas e acompanhamento e supervisão de riscos quanto às } \\
\text { atividades que foram planejadas. }\end{array}$ \\
\hline
\end{tabular}

QUADRO 6 - Gerenciamento de riscos nas indústrias com base no COSO/ERM

Fonte: dados da pesquisa.

A indústria " $A$ " planeja até seis meses antes para importações de matériaprima e faz pesquisas de mercado para saber se ganharia pedidos para atender as próximas coleções dos clientes. As demais também planejam, entretanto, duas ("D"

FERNANDES, F. C.; WRUBEL , F.; DALLABONA, L. F. Gerenciamento de riscos na cadeia de suprimentos de micro e pequenas empresas têxteis: discussão exploratória sobre oportunidades de pesquisa. Revista de Empreendedorismo e Gestão de Pequenas Empresas, v.4, n. 1, 2015. 
e "E") necessitam de softwares específicos para controle de estoque. A indústria "E" indicou que o controle e organização física ainda não estão adequados. Essas características instigam o desenvolvimento de pesquisas que analisem em empresas de outras categorias econômicas o processo de planejamento financeiro, de compras, estoques, identificando os principais riscos que incorrem quando, por exemplo, não há recursos financeiros suficientes para suprir maior demanda, quando a empresa não consegue atingir prazos de entregas que foram estipulados ou quando não possui um rigoroso sistema de controle de estoque.

Os resultados remetem a sugestões de futuras pesquisas. Quanto ao ambiente interno das indústrias analisadas, os riscos são identificados e dirigidos conforme perfil e valor dos gestores. Esses resultados sugerem estudos que envolvam outra amostra de micro e pequenas empresas e estudos para investigar como o risco é dirigido pelos gestores e o efeito da influência dos valores éticos, características do ambiente interno e externo, tempo de atuação das empresas e dos perfis dos gestores para tomar decisões que visem mitigar riscos internos.

Quanto à definição dos objetivos, a experiência dos gestores se sobressai nesse quesito, principalmente quanto ao planejamento (compra de matéria-prima e entrega de produtos), sendo necessário analisar em outras pesquisas, como as micro e pequenas empresas definem seus objetivos, tanto no que se refere a cadeia de suprimentos/logística quanto aos processos produtivos e se os riscos e mitigações são considerados.

Também na identificação de eventos, as empresas contam com a experiência dos gestores. Os fatores externos (econômicos e políticos) são identificados na medida em que ocorrem e os internos (compra de matéria-prima) são realizados conforme necessidade ou vendas. Um risco nesse processo refere-se ao aumento da demanda. Nesse contexto, podem ser desenvolvidos estudos analisando como as empresas identificam seus eventos internos (produção, tecnologia utilizada, pessoal qualificado) e externos (pedidos emergenciais), identificando os principais riscos e como as empresas agem para mitigá-los.

A avaliação e resposta aos riscos são identificadas e analisadas formalmente e informalmente, quando não planejados ou quando há imprevistos. Nestes casos, o 
gerenciamento é feito conforme prioridade estipulada pelos gestores. Pesquisas posteriores poderiam avaliar quais ações são tomadas por micro e pequenas empresas e o alinhamento com as suas estratégias.

As empresas possuem controles formais de compras de MP, pedidos, entrega e ordens de produção. Não se investigou quais políticas e procedimentos são estabelecidos por elas para garantir respostas aos riscos. Sugere-se investigação quanto a essa lacuna. Elas possuem controle de informação e comunicação por meio de fichas de controle, no qual as informações são registradas para posterior análise. A falta de sistema informatizado, principalmente quanto ao controle de estoque, não satisfaz a necessidade de gerenciamento.

As micro e pequenas empresas estudadas monitoram suas atividades e eventuais riscos principalmente no que se refere à compra de MP, estoques e entregas dos produtos aos clientes. Porém, há necessidade de outras pesquisas a fim de comparar os resultados, haja vista que micro e pequenas empresas apresentam estrutura, porte e gerenciamento diferenciado, dependendo da atividade econômica a que pertence.

\section{Considerações finais}

O estudo objetivou avaliar os riscos e mecanismos do gerenciamento de riscos inerentes à cadeia de suprimentos e logística, utilizados por micro e pequenas indústrias sediadas em Blumenau-SC. De igual forma, busca proporcionar discussão exploratória sobre oportunidades de pesquisas.

Neste sentido, desenvolveu-se uma pesquisa exploratória e qualitativa com aplicação de entrevista semiestruturada, utilizando questões que envolveram os oito componentes do COSO (2004) com enfoque para a cadeia de suprimentos e logística.

Os resultados demonstraram que as indústrias analisadas fornecem produtos para empresas têxteis de Blumenau, cidades vizinhas e outras regiões do Brasil. Atuam tanto no atacado quanto varejo, não possuem centros de distribuição e a maioria utiliza algum sistema informatizado para controles internos. Quanto aos 
processos da cadeia de suprimentos e logística, verificou-se que os principais fornecedores de matéria-prima são de São Paulo e as principais matérias são: poliéster, madeiras, produtos químicos, níquel, ferro, alumínio, tecido, inox e metais.

Os processos de industrialização, com exceção de uma indústria que terceiriza algumas peças, são desenvolvidos na indústria de acordo com os pedidos. As empresas destacam que a movimentação interna, tanto das matérias-primas quanto dos produtos acabados são feitos com total disciplina e cuidado, pois os produtos, na maioria dos casos, são frágeis. A entrega dos produtos acabados é feita por veículos próprios quando próximos a Blumenau e por transportadoras quando em outras regiões geográficas.

Os principais riscos identificados relacionam-se com a compra, o manuseio, o transporte e a qualidade das matérias-primas adquiridas, falta de conhecimento dos processos por parte dos clientes, softwares ineficientes, perdas no processo produtivo, competências dos funcionários, programação e prazos de entregas, processos complexos de importação.

Quanto as principais dificuldades na gestão de riscos, identificou-se a instabilidade do mercado, a constante busca por um bom relacionamento com o cliente e os softwares disponíveis para indústrias de máquinas. No que se refere ao monitoramento, mecanismos de mitigação e prevenção de riscos, constatou-se que no momento da compra de matéria-prima, os mecanismos de mitigação referem-se ao planejamento com base em controles de pedidos e negociações de preços, considerando a qualidade do produto em primeiro lugar. A empresa que importa matéria-prima mitiga eventuais riscos ao planejar com antecedência suas compras e envolvendo pessoas experientes para realizar o processo. Outro método de mitigação de riscos é buscar reinventar produtos com matérias-primas disponíveis e que satisfaz o cliente.

Com relação ao manuseio e estocagem de matérias-primas, destaca-se como mecanismos mitigadores, a utilização de EPIs e treinamento constante dos funcionários. O monitoramento por parte do supervisor é de extrema importância nesses processos. No que se refere aos riscos de entrega de mercadorias, a mitigação ocorre por meio de planejamento de compras e produção para atender o 
cliente no prazo programado e considera que os riscos inerentes ao transporte são mitigados pelo treinamento de funcionários (motoristas), destacando que os riscos de manuseio inadequados podem provocar altos prejuízos.

Conclui-se que o objetivo proposto pelo estudo foi alcançado, sendo que os riscos e mecanismos de mitigação foram identificados e analisados. Fez-se análise dos resultados buscando contribuir com os estudos correlatos realizados e com as apresentações de possibilidades de futuras pesquisas. Os riscos não foram quantificados, mensurados ou acompanhados durante as visitas, assim como não se avaliou se os procedimentos ou mecanismos utilizados pelas indústrias são eficientes, sugerindo, dessa forma, futuras pesquisas que envolvam tais questões.

As sugestões de pesquisas futuras apontadas, de maneira geral, podem ser realizadas em empresas da cadeia têxtil ou em outras amostras. $O$ desenvolvimento de mais estudos de gestão de riscos logísticos/suprimentos nas micro e pequenas empresas permitirá que os resultados possam ser discutidos e que as relações existentes nesses tipos de empresas possam ser melhor identificadas, explicadas e correlacionadas. Os resultados de pesquisas podem ser adotados na prática das empresas que buscam melhorar seus desempenhos e novas pesquisas podem surgir de necessidades práticas.

Por fim, é importante lembrar-se da realização do levantamento da gestão de riscos logístico/suprimentos de micro e pequenas empresas que atuam na cadeia têxtil de Blumenau/SC, que destacou diversas possibilidades de pesquisas futuras. A maior institucionalização da pesquisa em micro e pequenas empresas instigam possibilidades de comparações ou análises dos resultados, inclusive para relacionar com pesquisas em empresas de grande porte.

\section{Referências:}

ASSOCIAÇÃO DAS MICRO EMPRESAS, EMPRESAS DE PEQUENO PORTE, E EMPREENDEDORES INDIVIDUAIS DE BLUMENAU - AMPE. Empresas associadas. Disponível em: <http://www.ampeblumenau.com.br/portal/associados/empresas-associadas/>. Acesso em: 06 março de 2013. 
BALLOU, R. H. Logística empresarial: transportes, administração de materiais e distribuição física. Tradução Hugo T. Y. Yoshizaki. São Paulo: Atlas, 1993. 388 p.

BALLOU, R. H. Gerenciamento da cadeia de suprimentos/logística empresarial. Tradução de Raul Rubenich. Porto Alegre: Bookman, 2006.

BATISTA, F. F.; FREITAS, E. C.; SANTIAGO, J. S.; RÊGO, T. F. Uma investigação acerca da mortalidade das microempresas e empresas de pequeno porte da cidade de Sousa, PB. Revista de Administração, Contabilidade e Sustentabilidade, v. 2, n. 1, p.56-71, jan-abr, 2012.

BLOS, M. F.; WEE, M. Q. H. M.; WATANABE, K. Supply chain risk management (SCRM): a case study on the automotive and electronic industries in Brazil. Supply Chain Management: An International Journal, v. 14, n. 4, p. 247-252, 2009.

BOWERSOX, D. J.; CLOSS, D., J. Logistical management: the integrated supply chain process. New York: McGraw-Hill, 1996. 730 p.

CAVINATO, Joseph L. Supply chain logistics risks: from the back room to the board room. Internacional Journal of Physical Distribuition \& Logistics Management. v. 34 n. 5,2004 , p. $383-387$

COMMITTEE OF SPONSORING ORGANIZATIONS OF THE TREADWAYCOMMISSION - COSO. Enterprise Risk Management Integrated Framework. New York: COSO, 2004. Disponível em: <http://www.theiia.org/download.cfm?file=9229 >. Acesso em: 18 jun. 2012.

CHOPRA, S.; MEIND, P. Gestão da cadeia de suprimentos: estratégia, planejamento e operações. 4 ed. São Paulo: Pearson, 2011

CHRISTOPHER, M. Logística e gerenciamento da cadeia de suprimentos. São Paulo: Pioneira Thomson Learning, 2002.

DE PAZ, J. F.; BAJO, J.; BORRAJO, M. L.; CORCHADO, J. M. A Multiagent System for Web-Based Risk Management in Small and Medium Business. Highlights in PAAMS, AISC 89, pp. 9-17, 2011.

GITMAN, L. J. Princípios de administração financeira. 7. ed. São Paulo: Harbra, 1997.

GUIMARÃES, I. C. Uma pesquisa de campo sobre a contribuição da controladoria à gestão de riscos nas empresas não-financeiras de capital aberto da cidade de São Paulo. 2006. Dissertação (Mestrado em Controladoria e Contabilidade Estratégica) - Centro Universitário Álvares Penteado, São Paulo, 2006.

FERNANDES, F. C.; WRUBEL , F.; DALLABONA, L. F. Gerenciamento de riscos na cadeia de suprimentos de micro e pequenas empresas têxteis: discussão exploratória sobre oportunidades de pesquisa. Revista de Empreendedorismo e Gestão de Pequenas Empresas, v.4, n. 1, 2015. 
HARLAND, C.; BRENCHLEY, R.; WALKER, H. Risk in supply networks. Journal of Purchasing \& Supply Management, v. 9, p. 51-62, 2003.

HENSCHEL, T. Implementing a holistic risk management in Small and Medium Sized Enterprises (SMEs). In: 54th Annual World Conference on the International Council for Small Business, 21-24, June 2009.

JÜTTNER, U.; PECK, H.; CHRISTOPHER, M. Supply chain risk management: outlining an agenda for future research, International Journal of Logistics: Research and Applications. v. 6, n. 4, pp. 199-213, 2003

LEONE, N. M. C. P. G. As especificidades das pequenas e médias empresas. Revista de Administração, v. 34, n. 2, p. 91-94, abr./jun. 1999.

MATTOS, Marina Guimarães. Gestão de riscos em cadeias de suprimentos: estudo exploratório sobre a experiência brasileira. 117 f. 2011 . Dissertação (Mestrado em Geotecnia e Transportes) - Programa de Pós-Graduação em Geotecnia e Transportes. Universidade Federal de Minas Gerais, Belo Horizonte, MG, 2011.

MORAES, G. D. A.; ESCRIVÃO FILHO, E. A gestão da informação diante das especificidades das pequenas empresas. Ci. Inf., v. 35, n. 3, p. 124-132, set./dez. 2006.

OLSON, D. L.; WU, D. D. A review of enterprise risk management in supply chain. Kybernetes. v. 39, n. 5, p. 694-706, 2010,.

PAULO, W. L.; RODRIGUES, L. G. B.; FERNANDES, F. C.; EIDT, J. Riscos e controles internos: uma metodologia de mensuração dos níveis de controle de riscos empresariais. Revista de Contabilidade e Finanças, n. 43, p. 49-60, jan./abr., 2007.

PECK, $H$. Drivers of supply chain vulnerability: na integrated framework. International Journal of Physical Distribution \& Logistics Management. v. 35, n. 4, p. 210-232, 2005.

PORTER, M. Vantagem competitiva: criando e sustentando um desempenho superior. Tradução Elizabeth Maria de Pinho Braga. 24. ed. Rio de Janeiro: Campus, 1989. 512 p.

RAIHER, A. P. Desenvolvimento econômico de Santa Catarina e a ação do estado. Gestão \& Regionalidade. v. 29, n. 86, p. 4-18, maio/ago.2013.

RAUPP, F. M.; BEUREN, I. M. Metodologia da pesquisa aplicável às ciências sociais. In. BEUREN, I. M. (Org). Como elaborar trabalhos monográficos em contabilidade. 3. ed. São Paulo: Atlas, 2006.

FERNANDES, F. C.; WRUBEL , F.; DALLABONA, L. F. Gerenciamento de riscos na cadeia de suprimentos de micro e pequenas empresas têxteis: discussão exploratória sobre oportunidades de pesquisa. Revista de Empreendedorismo e Gestão de Pequenas Empresas, v.4, n. 1, 2015. 
SERVIÇO BRASILEIRO DE APOIO ÀS MICRO E PEQUENAS EMPRESAS SEBRAE. Critérios de Classificação de Empresas: El-ME-EPP. 2012. Disponível em: <http://www.sebrae-sc.com.br/leis/default.asp?vcdtexto=4154>. Acesso em: 08 fev. 2013.

SERVIÇO BRASILEIRO DE APOIO ÀS MICRO E PEQUENAS EMPRESAS SEBRAE. Blumenau. Santa Catarina em Números: Florianópolis/SC, 2010. 122 p. Disponível em: <http://www.sebrae-sc.com.br/scemnumero/arquivo/Blumenau.pdf> Acesso em: 06 mai. 2013.

SMIT, Y.; WATKINS, J. A. A literature review of small and medium enterprises (SME) risk management practices in South Africa. African Journal of Business Management, v. 6, n. 21, p. 6324-6330, 2012.

TURNER, R.; LEDWITH, A.; KELLY, J. Project management in small to mediumsized enterprises: Matching processes to the nature of the firm. International Journal of Project Management, v. 28, p. 744-755, 2010.

TUMMALA, R.; SCHOENHERR, T. Assessing and managing risks using the supply chain risk mangement process (SCRMP). Supply Chain Management: An International Journal, v. 16, n. 6, p. 474-483, 1996.

FERNANDES, F. C.; WRUBEL , F.; DALLABONA, L. F. Gerenciamento de riscos na cadeia de suprimentos de micro e pequenas empresas têxteis: discussão exploratória sobre oportunidades de pesquisa. Revista de Empreendedorismo e Gestão de Pequenas Empresas, v.4, n. 1, 2015. 